\title{
Pre-Analysis Plan for Setting Limits and their Relation to Well-being in End of Life Care
}

\section{Introduction}

In 2011, \$205 billion was spent on medical care for patients who were in their last year of life (Aldridge and Kelley, 2015). Medicare expenditures alone were responsible for $60 \%$ of this figure (Institute of Medicine, 2015). Given the magnitude of this expenditure and its expected increase (Lindgren, 2016) it is important to explore whether patient preferences for their own medical care at the end of life are satisfied. Though death at the end of every life is predictable with certainty, the death of each individual takes its own time, even as new medical technologies have made it possible for physicians to extend this time. Many of these technologies are high cost, and many also are emotionally, if not technically, difficult to stop once started. The result is that patients and their families are often asked to make difficult, sometimes excruciating decisions about limiting and ending intensive medical treatment as the time of death approaches. Added to these difficulties is the fact that the "end of life" is a time that is only known for certain retroactively.

\subsection{Advance Directives}

In the 1970 s, cardiopulmonary resuscitation became the normative treatment for patients undergoing cardiac arrest (American Heart Association, 2016). Unless a patient had a "Do Not Resuscitate" (or DNR) order, they would be resuscitated. Now, not only is CPR a norm, so too are long-term stays in the Intensive Care Unit (ICU), for which the mean cost per day is over $\$ 4,000$ (Dasta et al., 2005). However, implementing treatments as default ignores patient preferences, and it is both ethically and economically optimal to ensure that patient preferences about the level of care they receive are met.

Advance Directives, like DNRs, have made progress in ensuring that patient preferences are followed. However, changes in patient preferences between the time of writing and the time of treatment limit their applicability (Brown, 2012). More significant, decisions at the end of life are not made by the patient alone, but rather by a group involving some combination of the patient, their family, and the physician(s), all within the context of applicable insurance policy. Thus, advance directives - which focus exclusively on the patient - are insufficient in determining optimal outcomes for all parties involved. Even with regard to the focus on the patient, as Brown (2012) and others have suggested, advance directives are only successful when coupled with meaningful conversations among the patient, family, and health care team-both prior to and during treatment. In the absence of such conversations, patient preferences are too often followed haphazardly and inconsistently. 


\subsection{Cost versus Quality}

Recent research suggests that increasing expenditure on medical care at the end of life does not necessarily increase the quality of care, but frequently decreases it (Baiker et al. 2004). Part of what is driving this inverse correlation between cost and quality is the fact that many high-cost treatments can only be provided where patients least like to be when death approaches: in the intensive care unit of the hospital instead of at home or in a hospice unit. In addition, these treatments, once started, typically require patients and families to then choose to stop them, and this requirement often adds more stress to an already stressful circumstance. Also driving this phenomenon is the increasing default status of such treatments, the fact that patients and families typically have to opt out in advance in order not to receive them, and even then such directives are not certain to be followed.

\subsection{Opportunity Cost}

Government expenditure on medical care at the end of life is problematic from yet another angle: opportunity cost. A dollar spent on Medicare is (in theory, though not in practice due to earmarked funds (Kaiser Foundation, 2015)) a dollar that could be spent on another government program, such as the Department of Education. In other words, spending on medical care at the end of life is a tradeoff: the money could either be spent on the medical care, or put to another purpose-perhaps to improve underfunded schools, or improve medical care for children. Given that the median expenditure on medical care in the last year of life is $\$ 50,576$ (Aldridge and Kelley, 2015), even if a small fraction of individuals decided to reallocate the money that would be spent on their own medical care at the end of life to other purposes, the result would be a significant savings to insurers, including Medicare.

\section{Literature review}

\subsection{EOLC Costs}

Fisher et al. (2003), Barnato et al. (2004), Hogan et al. (2001), Lubitz and Riley (1993), and Zhang et al. (2009) argue that since EOLC spending is high, reducing EOLC spending is an efficient way to reduce total medical expenditures. Aldridge and Kelley (2015), however, challenge this notion by pointing out that though most decedents require high expenditures, most people who require high expenditures are not decedents (see Figure 1). Therefore, focusing on EOLC spending as a way to reduce total health care costs may not be the best option. However, reducing total health care costs is not the only rationale for addressing high EOLC costs: Baicker et al. (2004) show that the quality of EOLC is inversely correlated with its cost.

In seeking to reduce EOLC costs, we need to understand what drives them. On the demand side, Sally (2000) argues that changes in patient preferences for high cost EOLC as death approaches can explain the failure of advance directives to set limits on EOLC costs. On the supply side, Buntin and Huskamp (2002), Cutler et al. (2013), and Muhlbacher and Nubling (2011) argue that the structural aspects of the medical systemi.e., payment structures for physicians, physician beliefs about the efficacy of treatments, 
and hospice capacity - play a more significant role in determining EOLC expenditures than do patient preferences.

\subsection{EOLC Quality}

The economic study of medical care at the end of life is plagued by a series of methodological issues concerning how to measure quality care. Harris and Nease (1997) recognize the need for a consistent definition of "effective" care. Normand (2012) argues that standard notions of measurement of quality of life, based on the additivity of time rule, do not apply in an end of life context. Round (2012) recognizes problems with the Quality Adjusted Life Year (QALY) in the end of life context, but supports it over other measures of quality of life, such as the Palliative Care Yardstick. The literature does not reach a unanimous conclusion concerning the best measure of well-being at the end of life.

Ensuring quality of care at the end of life is an important ethical consideration. Callahan (2011) defines good EOLC as care - and not necessarily cure - that focuses on "the control of pain, the avoidance of unnecessary diagnostic procedures, wellcoordinated care, and family satisfaction" (p. 115). Moreover, Callahan (1983) argues that it is permissible - and, in some cases, desirable - to wean a dying patient off of basic nutrition and hydration. Meilaender (1984), however, counters Callahan by arguing that to withdraw food and water-even from an unconscious, dying patient - is akin to murder.

Callahan (2011) argues that EOLC is fundamentally a philosophical issue, not a management one. The philosophical issue at stake involves the question of the place of death in human life. Until the medical field addresses this issue directly, instead of instituting policies that come out of a confused understanding of the meaning of death, the state of EOLC will not improve. Daniels (1998) supports this view by showing how a purely economic perspective conflates the positive with the normative. Without a clear normative framework, any attempt to improve EOLC - including the social and political discourse examined in Brown (2012) —will flounder. Callahan (2011) and Brown (2012) argue that notions of agency underlie many of the discussions about EOLC. Callahan (2011) adds that it is crucial to make a distinction between a person who is living and one who is dying. Jakobsson et al. (2006) examine the role of the living versus dying distinction in shifting a patient from intensive treatment to palliative care.

Anecdotes from medical doctors serve to illustrate the complex and problematic nature of decisions about medical care at the end of life. Both Gawande (2010) and Zitter (2016) discuss the American emphasis on action and control. Their writings echo the sentiment of Callahan (2011) who laments that "Do Something" has become the overwhelming default option in EOLC. Zitter (2016) agrees and further describes how she and her assistants feel that they must keep the patient alive at all costs unless they hear otherwise from family members. As a doctor himself, Gawande (2015) notes a discrepancy between his desire as a doctor to over-test when in doubt and his resentment of over-testing as a patient or as the family member of a patient. 


\section{Study Rationale}

To illuminate some of the difficult issues surrounding decisions concerning medical care at the end of life, our research focuses on two goals: (i) to understand patient preferences in specific medical scenarios and (ii) to understand public attitudes about government policy that could set limits on spending on care at the end of life. A common confound in the study of preferences and attitudes is that respondents may be influenced by social norms, or even the survey itself (e.g., framing and social desirability bias). Also, stated preferences do not always predict behaviors, thus respondents may not know or be able to fully articulate their underlying preferences. Thus, in contrast to most studies on patient attitudes, we augment simple questions pertaining to preferences with a randomization design intended to elicit subtle beliefs and views. Specifically, we present respondents with primes intended to highlight a certain aspect of EOLC (e.g., fear of death, opportunity cost) and observe how shifting the patient's focus to the given topic affects their stated preferences. Additional detail on this design is discussed below.

The attitudes of citizens that we report can inform policy that determines what kinds of procedures, and in what circumstances, are funded by government programs such as Medicare and Medicaid. Specifically, we developed five testable hypotheses concerning patient preferences and public attitudes about medical spending at the end of life.

Our main hypothesis is that when patients are presented with a choice between specific care options they may not consider the full range of tradeoffs between money spent on medical care at the end of life and money spent on other purposes. As Kahneman (2003) and others have shown, decision-making is a murky process in which agents do not always rationally consider all possible outcomes. Moreover, insurance contracts affect patients' personal tradeoffs. Imagine a patient making the choice about a $\$ 20,000$ procedure that might extend her life. An uninsured patient faces the choice between the possibility of a longer life and using \$20,000 another way - for example leaving a larger bequest to heirs - whereas a Medicare insured patient faces no personal monetary opportunity cost. Suppose the patient would prefer a $\$ 10,000$ larger bequest to the procedure. In this case, there are potential mutual benefits to the patient and the Medicare system. This is an extreme and illustrative example, and not necessarily a desired approach due to ethical concerns. In addition to personal tradeoffs, we assess patient's attitudes to general social tradeoffs, such as the ability to repurpose Medicare EOLC expenses to other areas. To that end, we randomly present explicit information about the cost of treatment, as well as other options of how that money could be spent, to some respondents and compare their responses to others. The enables us to understand whether setting limits on EOLC spending is a pure cost on patients, or whether there may be some offsetting benefits - psychological or otherwise - accruing from alternative uses of funds. Our specific hypotheses are:

Hla: Mentioning another possible use of the money spent on end of life care will make patients more likely to accept limits on medical care at the end of life.

$H 1 b$ : Mentioning another possible use of the money spent on end of life care will make patients less likely to decide to take a particular treatment at the end of life. 
Second, decisions concerning medical care at the end of life are complicated due, in part, to the multi-party nature of these decisions. We hypothesize that various actors value medical care differently. This is important to understand in that decisions about EOLC involve patients, families, physicians, and often government and, indirectly, taxpayers. Thus, we test:

H2a: Given the same medical care scenario, patients, families, physicians, and public officials will choose different levels of treatment.

$H 2 b$ : Given the same medical care scenario, individuals will choose different levels of care depending on whether they imagine the scenario to be a general case, or about themselves specifically.

Third, we hypothesize that individuals will change their opinion about spending on medical care at the end of life when they are notified of specific facts regarding the nature of this type of medical care. If these hypotheses are true, they would suggest the need for programs which educate the public about these issues. Thus, H3:

H3a: When notified that studies that have shown a negative correlation between expenditure on medical care and quality of life, patients will be more likely to think that spending on care and quality of care are inversely correlated.

H3b: When notified of the cost of care, patients will be less likely to choose expensive treatment for themselves (personal), or see these expenditures as appropriate (general).

H3c: Presenting patients with clinical evidence regarding the effectiveness of treatment will change their decisions regarding whether to choose care for themselves (personal), or see a particular type of medical expenditure as appropriate (general).

H3d: Mentioning alternative methods of treatment (e.g., hospice) will make patients less likely to choose an expensive treatment option.

Fourth, we explore how various contextual factors - the role of doctors, views towards death and legal and social norms - play a role in decisions about medical care at the end of life. We test the following:

H4a: When a doctor states that a patient is dying, patients will be less likely to seek expensive medical treatment.

H4b: When a doctor advises against a treatment, patients will be less likely to seek it.

H4c: A fear of death is in part responsible for the resistance to the government setting limits about medical care at the end of life.

H4d: Making certain medical procedures not the legal default state of care will make patients less likely to choose these medical procedures. 
H4e: When patients are notified that certain medical procedures are not the social norm, they will be less likely to choose these procedures.

Fifth, we expect that advance directives will affect well-being — both in the present and in the predicted future - positively. Thus, hypothesis 5:

H5a: Individuals who have advance directives will have greater present evaluative well-being than those who do not.

H5b: Individuals who have advance directives will predict greater future evaluative well-being as they die.

H5c: Individuals who have advance directives will predict that their advance directive will positively impact the well-being of family and friends as they die.

H5d: Individuals who do not have advance directives will predict that their lack of advance directive will negatively impact the well-being of family and friends as they die.

In addition to the hypotheses described above, which are tested primarily through randomized manipulations, we also report summary statistics related to general attitudes towards end of life care, and explore how these attitudes vary by respondent demographics. Specifically, we investigate whether attitudes about medical care at the end of life correlate with age, gender, marital status, ethnicity, religious affiliation, religiosity, level of education, and income. We also look at whether the type of insurance an individual receives influences their decisions related to end of life care. Finally, we test whether having previously been involved in the end of life care process for a family or friend impacts attitudes about end of life care.

\section{Survey Design}

To test our hypotheses, we developed a survey on Google forms. Our desired sample consists of two subsets. First, we aim to survey citizens of the United States in general. Second, we aim to survey medical professionals specifically. Consequently, we have two different recruiting methods. To recruit citizens in general, we will post a link to the survey on Amazon Mechanical Turk (MTurk) where workers can complete the survey for $\$ 1.00$ compensation. To recruit medical professionals, we will send an email invitation to the survey to geriatricians and other medical professionals who deal with end of life care (we will purchase these emails from American Medical Association database). Medical professionals who fill out the survey will be entered into a lottery to win a $\$ 300$ Amazon gift card.

Upon entering the survey, each respondent is randomly assigned to see only one of the three survey versions. Each survey version has a similar structure and includes four parts: (i) demographic questions, (ii) well-being questions, (iii) attitudinal questions, and (iv) medical scenario questions (more on these sections below). The demographic, wellbeing, and attitudinal questions are consistent across each survey version. The medical scenario questions, however, change between survey versions, in a manner that will be 
described below in detail. By randomly assigning participants to see only one of the three sets of questions, we can detect the effect of differences in information provided in the scenarios on survey responses. In the analysis section, we refer the first survey version as "Treatment 1," the second as "Treatment 2," and the third as "Control."

The first part of the survey solicits basic demographic information. The second part consists of a series of questions concerning the relationship between advance directives and experiential and evaluative well-being in the present and future. All three versions of the survey contain the same demographic questions and the same questions about wellbeing.

The third part of the survey consists of attitudinal questions. This section asks participants to indicate on a five point Likert scale how much they agree with various statements concerning medical care at the end of life, such as "It is appropriate for the government to set limits on medical care at the end of life." In total across all survey versions, there are 43 of these attitudinal questions. To limit the length of the survey, we chose to assign one third of these attitudinal questions to each survey version. Thus, a single participant will see only one-third of the attitudinal questions. However, since participants are randomly assigned to survey versions, responses to each of these three sets of attitudinal questions will be representative of the response of the sample as a whole.

The fourth, and most substantial, section of the survey consists of a series of contrived medical scenarios in which the participant must make a decision. Our survey includes two sets questions concerning medical scenarios. The first set, consisting of 13 scenarios and corresponding questions, seeks to understand when individuals are willing to spend money on medical care for themselves, and when individuals deem spending on medical care socially responsible. For these kinds of scenarios, each respondent will randomly be assigned to a single version of each scenario. Each scenario is accompanied by two questions that remain the same for each respondent: first, a question about whether getting the treatment is socially responsible and, second, a question about whether the respondent would prefer to get the treatment if $\mathrm{s} /$ he were in the given scenario.

The second set of the fourth section, consisting of five of medical scenarios and corresponding questions, assess the degree to which preferences differ amongst patients, their families, physicians, and public officials who make policy concerning end of life care. For this set of questions, each respondent is shown the same version of each scenario and is asked a question about whether they would recommend treatment. However, the perspective from which the question is asked changes across each of the three survey versions, thus randomly assigning different perspectives to different respondents. This random assignment of perspective allows us to discern the effect of asking these questions from different perspectives.

Specific survey questions are presented in the Appendix. 


\section{Plan for Analysis}

The following section details our econometric approach.

\subsection{Hypothesis 1 - Opportunity Cost Matters}

To test H1a we estimate the model:

$$
\text { limit }=B_{0}+B_{1}(\text { Opportunity cost })+E_{1}
$$

where limit is a variable on a 1-5 scale that indicates how much a respondent agrees with the statement "It is appropriate for the government to set limits on how much it will contribute financially to medical care at the end of life." $B_{0}$ is the mean value of limit in the control version of the survey, and Opportunity cost is a dummy variable that takes the value of 1 when an opportunity cost is mentioned, 0 if otherwise.

To test H1b we estimate the model:

$$
\text { care }=B_{0}+B_{1}(\text { Opportunity cost })+E_{1}
$$

where care is a variable on a 1-5 scale that indicates how much a respondent agrees with the statement "It is appropriate for the patient to get the medical treatment in question for this situation." $B_{0}$ is the mean value of care in the control version of the survey, and Opportunity cost is a dummy variable that takes the value of 1 when an opportunity cost is mentioned, 0 if otherwise.

\subsection{Hypothesis 2 - Different Perspectives Mean Different Valuations}

In Scenario 14 through Scenario 18 of the survey (see Appendix), we present the same scenario and ask the respondent if they would recommend treatment while randomizing the perspective that the question is asked from. H2a implies that within each scenario, changes in perspectives will result in different likelihoods to recommend treatment. To test this hypothesis, we conduct unpaired t-tests between the mean of recommend (where recommend is a dummy variable that takes a value of 1 if the respondent recommends treatment, 0 if otherwise) between two perspectives.

$\mathrm{H} 2 \mathrm{~b}$ implies that for each of the 12 scenarios in Scenario Set I that ask a question from both a general and personal perspective, the answer from the general and personal perspective will be different. To test $\mathrm{H} 2 \mathrm{~b}$, we perform a paired t-test of the results of the general question compared to the personal question. The general variable is a response on a 1-5 scale indicating how much the respondent agrees with the general version of the question, "It is an appropriate expenditure of Medicare funds for this patient to get the operation." The personal variable is a response on a 1-5 scale to the question "If I were this patient, I think it is an appropriate expenditure of Medicare funds for me to get the operation." 


\subsection{Hypothesis 3 - Information Changes Decisions}

To test H3a we estimate the model:

$$
\text { inverse }=B_{0}+B_{1}(\text { Info }- \text { cost vs. quality })+E_{1}
$$

where inverse is a variable that indicates on a 1-5 scale how much a respondent agrees with the statement "Spending more money on end of life care leads to better care at the end of life." $B_{0}$ is the value of "inverse" when the respondent is asked the question without any prior information in the control version of the scenario. Info is a dummy variable that takes the value of 1 when the respondent is presented with a video which cites studies that have shown the inverse correlation between cost and quality of medical care, 0 if otherwise.

To test $\mathrm{H} 3 \mathrm{~b}$ we estimate the model:

$$
\text { care }=B_{0}+B_{1}(\text { Info }- \text { cost })+E_{1}
$$

where care is a variable on a 1-5 scale that indicates how much a respondent agrees with the statement "It is appropriate for the patient to get the medical treatment in question for this situation." $B_{0}$ is the value of care when the respondent is asked the question without any prior information in the control version of the scenario. Info is a dummy variable that takes the value of 1 when the respondent is presented with the cost of care, 0 if otherwise.

To test $\mathrm{H} 3 \mathrm{c}$ we estimate the model:

$$
\text { care }=B_{0}+B_{1}(\text { Info }- \text { clinical evidence })+E_{1}
$$

where care is a variable on a 1-5 scale that indicates how much a respondent agrees with the statement "It is appropriate for the patient to get the medical treatment in question for this situation." $B_{0}$ is the value of care when the respondent is asked the question without any prior information in the control version of the scenario. Info is a dummy variable that takes the value of 1 when the respondent is presented with information on the clinical effectiveness of the procedure, 0 if otherwise.

To test H3d we estimate the model:

$$
\text { care }=B_{0}+B_{1}(\text { Hospice })+E_{1}
$$

where care is a variable on a 1-5 scale that indicates how much a respondent agrees with the statement "It is appropriate for the patient to get the medical treatment in question (i.e., not hospice) in this scenario." $B_{0}$ is the mean value of care in the control version of the survey, and Hospice is a dummy variable that takes the value of 1 when the possibility of hospice care mentioned, 0 if otherwise. 


\subsection{Hypothesis 4 - Contextual Factors Change Preferences}

To test H4a we estimate the model:

$$
\text { care }=B_{0}+B_{1}(\text { Dying })+E_{1}
$$

where care is a variable on a 1-5 scale that indicates how much a respondent agrees with the statement "It is appropriate for the patient to get the medical treatment in question for this situation." $B_{0}$ is the mean value of care in the control version of the scenario, and "Dying" is a dummy variable that takes the value of 1 when the doctor says the patient is dying, 0 if otherwise.

To test $\mathrm{H} 4 \mathrm{~b}$ we estimate the model:

$$
\text { care }=B_{0}+B_{1}(\text { Against care })+E_{1}
$$

where care is a variable on a 1-5 scale that indicates how much a respondent agrees with the statement "It is appropriate for the patient to get the medical treatment in question for this situation." $B_{0}$ is the mean value of care in the control version of the scenario, and "Against" is a dummy variable that takes the value of 1 when the doctor advises against care, 0 if otherwise.

To test $\mathrm{H} 4 \mathrm{c}$ we estimate the model:

$$
\text { limit }=B_{0}+B_{1}(\text { Scary death })+B_{2}(\text { Peaceful death })+E_{1}
$$

where limit is a variable on a 1-5 scale that indicates how much a respondent agrees with the statement "It is appropriate for the government to set limits on how much it will contribute financially to medical care at the end of life." $B_{0}$ is the value of limit when there in the control version of the survey, i.e., when there is no video. Scary death is a dummy variable that is 1 when a video of a scary death is shown, 0 if otherwise. Peaceful death is a dummy variable that is 1 when a video of a peaceful death is shown, 0 if otherwise.

To test H4d we estimate the model:

$$
\text { sign }=B_{0}+B_{1}(\text { Default is no care })+E_{1}
$$

where sign is a dummy variable that takes a value of 1 if the respondent chooses to sign a special release that indicates that they would not like to receive the default option, 0 if otherwise. $B_{0}$ is the value of sign when the default option is to receive care. Default is no care is a dummy variable that takes the value of 1 when receiving care is not the default option, 0 if otherwise. In other words, when care is not the default option, the patient must sign the release to receive care.

To test H4e we estimate the model: 


$$
\text { care }=B_{0}+B_{1}(\text { Social norm care })+B_{2}(\text { Social norm hospice })+E_{1}
$$

where care is a variable on a 1-5 scale that indicates how much a respondent agrees with the statement "It is appropriate for the patient to get the medical treatment in question for this situation." Social norm care is a dummy variable that takes the value of 1 when the social norm is to receive care, 0 if otherwise. Social norm hospice is a dummy variable that takes the value of 1 when hospice is the social norm, 0 if otherwise. We leave out the neutral (i.e., control) condition in which there is no mention of a social norm. Therefore, $B_{0}$ is the mean of care when no social norm is mentioned.

\subsection{Hypothesis 5 - Advance Directives are Good for Well-being}

To test this hypothesis, we do not use an imagined scenario but rather ask respondents directly whether they have an advanced directive or not.

To test H5a we estimate the model:

$$
\text { well-being }=B_{0}+B_{1}(\text { Advance directive })+E_{1}
$$

where well-being indicates a respondents valuation of their own present evaluative wellbeing on a $0-10$ scale. $B_{0}$ is the mean well-being for respondents without an advance directive. Advance directive is a dummy variable that is 1 when a respondent has an advance directive, 0 if otherwise.

To test $\mathrm{H} 5 \mathrm{~b}$ we estimate the model:

$$
\text { well-being }=B_{0}+B_{1}(\text { Advance directive })+E_{1}
$$

where well-being is indicates a respondent's valuation of their own future evaluative well-being while they are in the process of dying on a 0-10 scale. $B_{0}$ is the mean wellbeing for respondents without an advance directive. Advance directive is a dummy variable that is 1 when a respondent has an advance directive, 0 if otherwise.

We test $\mathrm{H} 5 \mathrm{c}$ by looking at the mean value of responses to our question which asks respondents with advance directives to report to what degree they think that their advance directive will contribute to the well-being of their family and friends as they die. If the mean is greater than 3 (the middle point on the Likert scale), then the hypothesis holds.

We test H5d by looking at the mean value of responses to our question which asks respondents without advance directives to report to what degree they think that their lack of advance directive will decrease the well-being of their family and friends as they die. If the mean is greater than 3 (the middle point on the Likert scale), then the hypothesis holds.

\subsection{Demographics Analysis}


To explore how general attitudes vary with demographics, we estimate:

$$
\text { limit }=B_{0}+B_{1} X+E_{1}
$$

where limit is a variable on a 1-5 scale that indicates how much a respondent agrees with the statement "It is necessary to set limits on how much medical care people receive at the end of life." $X$ is a variable pertaining to the respondents' demographic characteristics.

\section{Works Cited}

Aldridge, Melissa, and Amy Kelley. 2015. "The Myth Regarding the High Cost of Endof-Life Care." American Journal of Public Health 105 (12): 2411-16.

American Heart Association. 2015. "History of CPR." http://cpr.heart.org/AHAECC/CPRAndECC/AboutCPRFirstAid/HistoryofCPR/UC M_475751_History-of-CPR.jsp.

Baicker, Katherine, and Amitabh Chandra. 2004. "Medicare Spending, The Physician Workforce, and Beneficiaries' Quality of Care." Health Affairs Online (April). http://content.healthaffairs.org/content/early/2004/04/07/hlthaff.w4.184.full.pdf + htm 1.

Barnato, Amber, Mark McClellan, Christopher Kagay, and Alan Garger. 2004. "Trends in Inpatient Treatments Intensity among Medicare Beneficiaries at the End of Life." Health Services Research 39 (2): 363-76.

Brown, Lawrence D. 2012. "Stealing on Insensibly: End of Life Politics in the United States." Health Economics, Policy and Law 7 (4): 467-483. doi:10.1017/S1744133112000254.

Buntin, Melinda Beeuwkes, and Haiden Huskamp. 2002. "What Is Known About the Economics of End-of-Life Care for Medicare Beneficiaries?" The Gerontologist 42 (3): 40-48. doi:10.1093/geront/42.suppl_3.40.

Callahan, Daniel. 1983. "On Feeding the Dying." The Hastings Center Report 13 (5): 22 22. doi:10.2307/3560573.

- 2011. "End-of-Life Care: A Philosophical or Management Problem?" Journal of Law, Medicine, and Ethics 39 (2): 114-20.

Cutler, David, Jonathan Skinner, Ariel Dora Stern, and David Wennberg. 2013. "Physician Beliefs and Patient Preferences: A New Look at Regional Variation in Health Care Spending." National Bureau of Economic Research, Inc, NBER Working Papers: 19320. doi:http://www.nber.org/papers/w19320.pdf.

Daniels, Norman. 1998. "Does Economics Provide a Unified Account of Aging Behavior and Aging Policy?” Edited by Richard Posner. Ethics 108 (3): 569-85.

Dasta, Joseph F., Trent P. McLaughlin, Samir H. Mody, and Catherine Tak Piech. 2005. "Daily Cost of an Intensive Care Unit Day: The Contribution of Mechanical Ventilation." Critical Care Medicine 33 (6): 1266-71.

Fisher, Elliott, David Wennberg, Therese Stukel, and Daniel Gottlieb. 2003. "The Implications of Regional Variations in Medicare Spending. Part 1: The Content, Quality, and Accessibility of Care.” Annals of Internal Medicine 138 (4): 273-88. 
Gawande, Atul. 2010. "Letting Go.” The New Yorker, August 2. http://www.newyorker.com/magazine/2010/08/02/letting-go-2.

Harris, Ryan A., and Robert F. Nease Jr. 1997. "The Importance of Patient Preferences for Comorbidities in Cost-Effectiveness Analyses." Journal of Health Economics 16 (1): 113-19. doi:10.1016/S0167-6296(96)00510-3.

Hogan, Christopher, June Lunney, Jon Gabel, and Joanne Lynn. 2001. "Medicare Beneficiaries' Costs of Care in the Last Year of Life." Health Affairs 20 (4): 188-95. Institute of Medicine, and Committee on Approaching Death: Addressing Key End of LifeIssues. 2015. Dying in America: Improving Quality and Honoring Individual Preferences Near the End of Life. 1 edition. Washington, D.C: National Academies Press.

Jakobsson, Eva, Ingrid Bergh, Fannie Gaston-Johansson, Carl-Magnus Stolt, and Joakim Öhlén. 2006. "The Turning Point: Clinical Identification of Dying and Reorientation of Care." Journal of Palliative Medicine 9 (6): 1348-58. doi:10.1089/jpm.2006.9.1348.

Lindgren, Bjørn. 2016. "The Rise in Life Expectancy, Health Trends among the Elderly, and the Demand for Health and Social Care." National Institute of Economic Research Working paper (142). http://www.konj.se/download/18.45f4dff21532e40aa884dc49/1456823350974/Work ing-paper-142-The-rise-in-Life+Expectancy-health-trends-among-the-elderly-andthe-demand-for-health-and-social-care.pdf.

Lubitz, James, and Gerald Riley. 1993. "Trends in Medicare Payments in the Last Year of Life." New England Journal of Medicine 328 (15): 1092-96.

Meilaender, Gilbert. 1984. "On Removing Food and Water: Against the Stream." The Hastings Center Report 14 (6): 11-13. doi:10.2307/3561735.

Muhlbacher, Axel C., and Matthias Nubling. 2011. "Analysis of Physicians' Perspectives versus Patients' Preferences: Direct Assessment and Discrete Choice Experiments in the Therapy of Multiple Myeloma." European Journal of Health Economics 12 (3): 193-203. doi:http://link.springer.com/journal/volumesAndIssues/10198.

Normand, Charles. 2012. "Setting Priorities in and for End-of-Life Care: Challenges in the Application of Economic Evaluation." Health Economics, Policy and Law 7 (4): 431-439. doi:10.1017/S1744133112000229.

Round, Jeff. 2012. "Is a QALY Still a QALY at the End of Life?" Journal of Health Economics 31 (3): 521-27. doi:10.1016/j.jhealeco.2012.01.006.

Sally, David. 2000. "Confronting the Sirens: Rational Behavior in the Face of Changing Preferences." Journal of Institutional and Theoretical Economics (JITE) / Zeitschrift Für Die Gesamte Staatswissenschaft 156 (4): 684-714.

Zhang, Baohui et al. 2009. "Health Care Costs in the Last Week of Life: Associations With End-of-Life Conversations." Archives of Internal Medicine 169 (5): 480-88.

Zitter, Jessica Nutik. 2016. "In the Hospital, Resisting the Urge to Do More." New York Times, sec. Well Blog. http://well.blogs.nytimes.com/2016/04/14/in-the-hospitalletting-nature-takes-its-course/. 


\section{Appendix}

\subsection{Figures}

Figure 1. High cost vs. End of life population

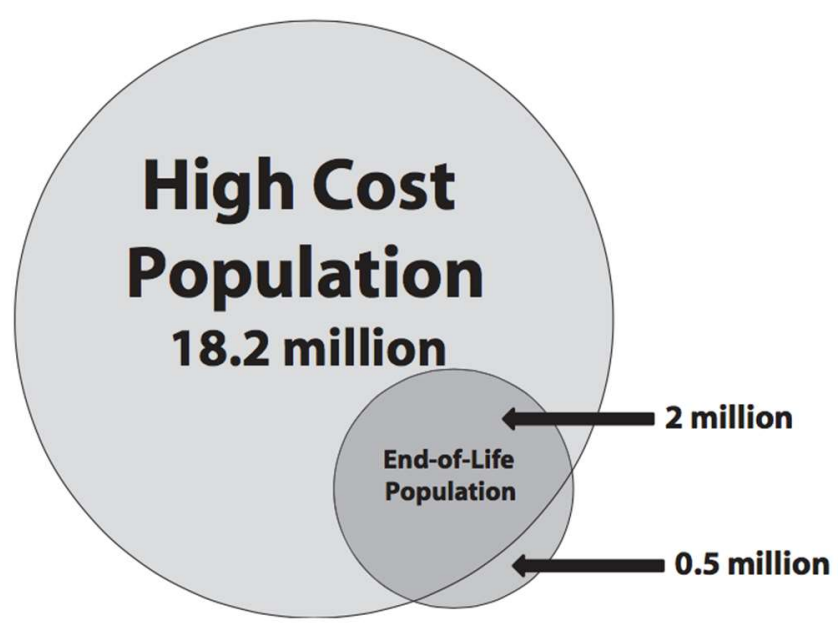

Source. Total population and health care costs were obtained from 2011 Medical Expenditure Panel Survey data ${ }^{21}$ adjusted to include the nursing home population. ${ }^{24}$ The distribution of total costs for the end-of-life population was estimated from Health and Retirement Study data linked to Medicare claims data, adjusted to include non-Medicare payers $^{11}$ and adjusted to 2011 dollars via the Bureau of Labor Statistics Consumer Price Index.

FIGURE 1-Estimated overlap between the population with the highest health care costs and the population at the end of life: United States, 2011.

Source: Aldridge and Kelley (2015)

\subsection{Survey Question Text}

As described in Section 4, each respondent will be randomly assigned to see one of three survey versions: (i) Control, (ii) Treatment 1, and (iii) Treatment 2.

\subsubsection{Survey Version: Control}

\subsubsection{Survey Section \#1: Demographic}

1. What is your age?

2. What is your sex?

3. What is your marital status?

4. What is your ethnicity?

5. What is your religion?

6. How often do you participate in an organized religious activity?

7. What is your highest level of education? 
8. How many children do you have?

9. What is your income?

10. How many bedrooms are in your home?

11. What kind of health insurance do you have?

12. If you purchase directly health insurance for yourself or family members, do you receive a subsidy for this purchase via the affordable care act?

13. I have had a substantive conversation with my family, friends, and/or my physician about my $\square$ preferences for end of life care.

14. I have paid directly to provide care for someone at the end of life.

15. Which (if any) of your parents are still living?

16. Have you ever made decisions about end of life care for a family member or a friend?

17. If you answered yes to the above, what kind of health insurance did the person whom you cared for have?

18. Have you ever been hospitalized?

19. Have you taken a serious, injurious fall or been in some other kind of accident?

20. Have you ever been immobile?

21. Are you a physician?

22. If you answered yes to the above, do you regularly deal with situations in which patients are at the end of life?

\subsubsection{Survey Section \#2: Well-being}

1. Imagine a ladder with ten steps numbered from zero at the bottom to ten at the top. The top represents the best possible life for you and the bottom represents the worst possible life for you. On which step of the ladder would you say you personally stand at this time?

2. An advance directive is a legal document that specifies a person's preferences about the kind of care they would like to receive at the end of life. Do you have an advance directive?

3. If you answered yes to the above, where do you think you would stand these days on the ladder without the advance directive?

4. If you answered no to the above, where do you think you would stand these days on the ladder with an advance directive?

5. If you answered yes to the above: My advance directive will contribute positively to the well- being of my family and friends as I am in the process of dying.

6. If you answered no the above: Not having an advance directive will have negative impacts on $\square$ the well-being of my family and friends as I am in the process of dying.

7. If you have spent time caring for a dying friend or relative: Where would you place yourself on $\square$ the ladder during the time you were caring for your dying friend or relative?

8. On which step do you think you will stand as you are in the process of dying?

\subsubsection{Survey Section \#3: Attitudinal}

1. Government health care (e.g., Medicare and Medicaid) is a public resource.

2. No one can say for sure how much longer a person can live. 
3. The economic development of the community is more important than the health care needs of the oldest members of the community.

4. Cost is an important factor when making decisions about end of life care.

5. If my health care is a financial burden to my family, I am willing to go without it.

6. My family, friends, and physicians know and agree with my preferences about end of life care.

7. The more agency I have in making decisions about EOLC, the happier I will be in the process $\square$ of dying.

8. There is a clear point at which a person can be said to transition from the process of living to $\square$ the process of dying.

9. Even if the chances of benefit from a medical treatment are very low, it is worth a try.

10. I expect that I will place the same value on autonomy in decision making about end of life care $\square$ at the end of life as I do now.

11. I would forgo medical care at the end of life if I knew that the money saved was going to my heirs.

12. Physicians tend to overestimate how long a patient with a terminal illness will live.

13. Part of what it means to take care of elderly people is to provide them with whatever medical $\square$ care they need without regard for cost.

14. The promotion of public health is more important than extending the lives of individuals over a certain age.

\subsubsection{Survey Section \#4: Medical scenarios}

\subsection{Medical scenarios subsection \#1}

1. Health care is a public good. How much (1-5) do you agree with the statement?

2. John is 90 years old and presently in the midst of an extended stay in the ICU, where he requires a respirator to breathe. He does not have an advance directive to indicate his treatment preferences. The cost of keeping John alive is $\$ 6000$ per day. How much (1-5) do you agree with the statement?

3. Mark is 90 years old and presently in the midst of an extended stay in the ICU, where he requires a respirator to breathe. The cost of his hospital stay is $\$ 6,000$ per day. Mark is currently unable to make decisions about his care, and thus his family is legally responsible for determining the course of action. If they continue his care, he will likely remain alive but is not expected to improve. The doctor has informed the family that, given Mark's condition, it would be legal and he would be willing to discontinue the use of the respirator if the family chose that option. If you would discontinue the respirator, what would you rather have your family spend money on?

4. Please watch the following video of nature scenerey. How much (1-5) do you agree with the statement?

5. Please watch the following video of nature scenerey. How much (1-5) do you agree with the statement?

6. Please watch the following video of nature scenerey. How much (1-5) do you agree with the statement? 
7. Sue has pancreatic cancer. Her doctor offers to perform an intensive surgery to remove some of the cancer. Ninety percent of people who get this operation live through it. The operation is covered fully by Medicare. If Sue survives, the operation is expected to extend her life by 6 months. Sue and her family decide that Sue will get the surgery. How much (1-5) do you agree with the statement?

8. Helen is 60 years old, has HER2-overexpressing breast cancer, and is currently receiving chemotherapy. Her doctor thinks that if she takes an anti-cancer drug called Trastuzumab (brand name: Herceptin) in addition to her chemotherapy, her chances of being alive in ten years will increase. It would cost $\$ 64,000$ to add Herceptin to her treatment regimen for one year. How much (1-5) do you agree with the statement?

9. Jane cannot breathe without a respirator. The doctor says they can continue doing everything possible to keep Jane alive in the ICU. The cost of keeping Jane alive in the ICU is $\$ 8,000$ per day. How much $(1-5)$ do you agree with the statement?

10. Shelby has stomach cancer and is in in her third round of chemotherapy. She has the opportunity to receive an invasive surgical procedure that would attempt to remove the tumor. The treatment would cost $\$ 100,000$ and has a $50 \%$ chance of extending her life for one year. How much (1-5) do you agree with the statement?

11. George is 80 years old and has a long history of heart disease and other ailments. He had a heart attack last Wednesday and will likely die in the next two weeks without an operation. The operation costs $\$ 80,000$. How much (1-5) do you agree with the statement?

12. Robert is 93 years old and has an inoperable tumor on his neck. As a result of the tumor's continued growth, sometime within the next four months Robert will require a ventilator in order to remain alive. Unless Robert specifies in advance that he does not want to receive mechanical ventilation and its associated life-saving care, it will be provided. In order not to receive mechanical ventilation and its associated life-saving care, Robert would need to sign a release specifically requesting that doctors not provide it. If you were the patient in this situation, would you sign the release?

13. James is 87 and has late-stage kidney cancer. An intensive series of surgeries would give James a 50\% chance of extending his life for one year. The surgeries would cost $\$ 60,000$. James also has the option of forgoing treatment and entering hospice care. How much (1-5) do you agree with the statement?

\subsection{Medical scenarios section \#2}

14. Erica is 75 and has a rare and fatal disease that affects the ability of her lungs to function properly. Treatment for the disease involves a series of intensive procedures which cost $\$ 40,000$ and doctors expect that the procedures will extend Erica's life by about two years. If you were a family member, would you recommend treatment?

15. Alex is 25 and was in a car accident that caused serious spinal damage. Alex will almost certainly die in the next week without an operation. If Alex receives the operation, it will cost $\$ 50,000$ and he will still be paralyzed. If you were the physician, would you recommend treatment?

16. Sasha is 18 and was swimming in a fast-flowing river and hit her head, causing her to fall unconscious and nearly drown. She was retrieved from the water and 
kept alive via CPR until the ambulance arrived. Now Sasha is in a coma. Doctors expect that they can bring Sasha out of the coma through various intensive treatments, which will cost upwards of $\$ 100,000$. Doctors say that if Sasha emerges from the coma, she will have severe brain damage for the rest of her life as a result of the period of hypoxemia. Imagine you are a public official in charge of managing health care costs. Would you recommend treatment in this situation?

17. Joe is 40 years old and has late stage colon cancer. With standard treatment Joe's life expectancy is 6 months. Doctors offer to give Joe a new procedure that costs $\$ 60,000$ and that may increase his life expectancy to 12-16 months. If you were the patient in this situation, would you prefer treatment?

18. Naomi is 65 years old and has chronic obstructive pulmonary disease - a lung disease which makes it hard to breathe. Her disease is in a late stage and doctors expect that she will die within one month. Doctors have tried several drugs to slow the progression of Naomi's disease but none have worked so far. There are still a few more that they can try. If Naomi is nearing death, she has the option of getting care in the ICU at the cost of $\$ 5,000$ per day while doctors try more drugs to treat her disease. If you were a family member, would you recommend treatment?

\subsubsection{Survey Version: Treatment 1}

\subsubsection{Survey Section \#1: Demographic} Same as Control

\subsubsection{Survey Section \#2: Well-being} Same as Control

\subsubsection{Survey Section \#3: Attitudinal}

1. Only a doctor can decide whether a medical intervention is appropriate.

2. My family is willing to spend as much money as they possibly can on my medical care if doing so will extend my life.

3. It is necessary to set limits on how much medical care people receive at the end of life.

4. Patients with terminal illnesses tend to overestimate how long they will live.

5. The health care needs of children are more important than the health care needs of elderly people.

6. It is important to know the cost of medical care at end of life regardless of who pays for it.

7. It is important to have a public policy that sets limits on Medicare spending for patients at the end of life.

8. It is unethical to set limits on how much medical care people receive at the end of life.

9. When receiving care at the end of life, it is important to consider how much of a financial burden one is incurring on society.

10. The appropriate level of health care at the end of life can only be determined by the patient $\square$ receiving the care. 
11. It is easier for me to accept limits on how much medical care I can receive at the end of life if $\square$ everyone else accepts the same limits.

12. I know my own preferences regarding end of life care.

13. My death is an event that will happen far in the future.

14. It is important to limit spending on health care when death is imminent.

15. I would forgo medical care at the end of life if I knew that the money saved was applied directly to help someone else in need.

\subsubsection{Survey Section \#4: Medical scenarios}

\subsection{Medical scenarios section \#1}

1. Health care is a public good. Medicare is funded with taxpayer dollars. Taxpayer dollars can be used for various public services, including education, transportation infrastructure, unemployment insurance, national defense, etc. How much (1-5) do you agree with the statement?

2. John is 90 years old and presently in the midst of an extended stay in the ICU, where he requires a respirator to breathe. He does not have an advance directive to indicate his treatment preferences. The cost of keeping John alive is $\$ 6000$ per day. Medicare expenditures come from the same budget as other government programs and services. The money used to keep John alive could be used to benefit other citizens. How much (1-5) do you agree with the statement?

3. Mark is 90 years old and presently in the midst of an extended stay in the ICU, where he requires a respirator to breathe. The cost of his hospital stay is $\$ 6,000$ per day. The money that Mark's family is spending on his medical care comes out of Mark's savings and could be used instead for other things, such as to help fund the college education of Mark's grandchildren. Mark is currently unable to make decisions about his care, and thus his family is legally responsible for determining the course of action. If they continue his care, he will likely remain alive but is not expected to improve. The doctor has informed the family that, given Mark's condition, it would be legal and he would be willing to discontinue the use of the respirator if the family chose that option. If you would discontinue the respirator, what would you rather have your family spend money on?

4. Ensuring that children have good medical care is extremely beneficial to society. Please watch the video below about preventive medical care for children. How much (1-5) do you agree with the statement?

5. Please watch the video below (to 1:04) about end of life care spending. How much (1-5) do you agree with the statement?

6. Sue has pancreatic cancer. Her doctor offers to perform an intensive surgery to remove some of the cancer. Ninety percent of people who get this operation live through it. The operation, which costs $\$ 90,000$, is covered fully by Medicare. If Sue survives, the operation is expected to extend her life by 6 months. Sue and her family decide that Sue will get the surgery. How much (1-5) do you agree with the statement?

7. Helen is 60 years old, has HER2-overexpressing breast cancer, and is currently receiving chemotherapy. A research study published in The Journal of Clinical Oncology in 2014 found that for treatment of the specific kind of breast cancer Helen has, "adding a year of Herceptin (trastuzumab) to standard chemotherapy 
improved overall survival by 37 percent. The addition of Herceptin also boosted 10 -year overall survival rates from 75 percent to 84 percent. And the 10 -year disease-free survival rate went from 62 percent to 74 percent for those also taking Herceptin." It would cost $\$ 64,000$ to add Herceptin to her treatment regimen for one year. How much (1-5) do you agree with the statement?

8. Death can be scary - it can be a long and painful process, or come suddenly and unexpected. Regardless of how it manifests, death is the worst possible thing that can happen to a person. As such, it is noble and fitting to resist death as long as possible. Please watch the following clip (until 0:42) from the movie Wit on what it is like to die from cancer. How much (1-5) do you agree with the statement?

9. Jane cannot breathe without a respirator. Her doctor says Jane is dying. Her doctor also says they can continue doing everything possible to keep Jane alive in the ICU. The cost of keeping Jane alive in the ICU is $\$ 8,000$ per day and is paid for by Medicare. How much (1-5) do you agree with the statement?

10. Shelby has stomach cancer and is in in her third round of chemotherapy. Shelby has the option of hospice care, which means that Shelby will receive no treatments that attempt to cure her cancer but instead will receive treatments that aim to ease her pain and improve her daily functioning and quality of remaining life. She also has the opportunity to receive an invasive surgical procedure that would attempt to remove the tumor. The procedure would cost $\$ 100,000$ and has a $50 \%$ chance of extending her life for one year. Hospice care would cost a fraction of the procedure. How much (1-5) do you agree with the statement?

11. George is 80 years old and has a long history of heart disease and other ailments. He had a heart attack last Wednesday and will likely die in the next two weeks without an operation. The operation costs $\$ 80,000$. George's doctors however consider that George is too frail to survive the necessary anesthesia, and have advised him against the operation. How much (1-5) do you agree with the statement?

12. Robert is 93 years old and has an inoperable tumor on his neck. As a result of the tumor's continued growth, sometime within the next four months Robert will require a ventilator in order to remain alive. Unless Robert specifies in advance that he wants to receive mechanical ventilation and its associated life-saving care, it will not be provided. To receive mechanical ventilation and its associated life-saving care Robert would need to sign a release specifically requesting that doctors provide it. If you were the patient in this situation, would you sign the release?

13. James is 87 and has late-stage kidney cancer. An intensive series of surgeries would give James a $50 \%$ chance of extending his life for one year. The surgeries would cost $\$ 60,000$. James also has the option of forgoing treatment and entering hospice care. A large number of patients in similar situations choose to undergo treatment instead of hospice. How much (1-5) do you agree with the statement?

\subsection{Medical scenarios section \#2}

14. Erica is 75 and has a rare and fatal disease that affects the ability of her lungs to function properly. Treatment for the disease involves a series of intensive procedures which cost $\$ 40,000$ and doctors expect that the procedures will extend 
Erica's life by about two years. If you were the patient in this situation, would you prefer treatment?

15. Alex is 25 and was in a car accident that caused serious spinal damage. Alex will almost certainly die in the next week without an operation. If Alex receives the operation, it will cost $\$ 50,000$ and he will still be paralyzed. If you were a family member, would you recommend treatment?

16. Sasha is 18 and was swimming in a fast-flowing river and hit her head, causing her to fall unconscious and nearly drown. She was retrieved from the water and kept alive via CPR until the ambulance arrived. Now Sasha is in a coma. Doctors expect that they can bring Sasha out of the coma through various intensive treatments, which will cost upwards of $\$ 100,000$. Doctors say that if Sasha emerges from the coma, she will have severe brain damage for the rest of her life as a result of the period of hypoxemia. If you were the physician, would you recommend treatment?

17. Joe is 40 years old and has late stage colon cancer. With standard treatment Joe's life expectancy is 6 months. Doctors offer to give Joe a new procedure that costs $\$ 60,000$ and that may increase his life expectancy to 12-16 months. Imagine you are a public official in charge of managing health care costs. Would you recommend treatment in this situation?

18. Naomi is 65 years old and has chronic obstructive pulmonary disease - a lung disease which makes it hard to breathe. Her disease is in a late stage and doctors expect that she will die within one month. Doctors have tried several drugs to slow the progression of Naomi's disease but none have worked so far. There are still a few more that they can try. If Naomi is nearing death, she has the option of getting care in the ICU at the cost of $\$ 5,000$ per day while doctors try more drugs to treat her disease. If you were the patient in this situation, would you prefer treatment?

\subsubsection{Survey Version: Treatment 2}

\subsubsection{Survey Section \#1: Demographic Same as Control}

\subsubsection{Survey Section \#2: Well-being} Same as Control

\subsubsection{Survey Section \#3: Attitudinal}

1. It is appropriate for the government to set policies that limit spending on Medicare.

2. Taxpayer dollars are a public resource.

3. More expensive medical care at the end of life can help you have a more positive experience of $\square$ well-being at the end of life.

4. People who have lived a long life have less claim on health care resources than younger $\square$ people who haven't yet had the chance to achieve their personal goals.

5. A person who is living should receive more intense treatment than a person who is dying. 
6. I am willing to spend as much money as I possibly can on medical care if doing so will extend my life.

7. The government should have a say in whether a medical intervention is appropriate.

8. If a treatment covered by Medicare is not likely to work for a particular patient, it is a waste of $\square$ taxpayer money trying it.

9. If my health care is a financial burden to my country, I am willing to go without it.

10. I expect that I will place the same value on money at the end of life as I do now.

11. More expensive medical care at the end of life means better medical care.

12. If a person is not able to afford directly the cost of a medical treatment, they should not get the $\square$ treatment.

13. If you are a physician: I have a good understanding of my patients' preferences about end of $\square$ life care.

14. Only a patient and the family can decide whether a medical intervention is appropriate.

\subsubsection{Survey Section \#4: Medical scenarios}

\subsection{Medical scenarios section \#1}

1. Health care is a public good. Medicare is funded with taxpayer dollars. Taxpayer dollars can be used for various public services, including education, transportation infrastructure, unemployment insurance, national defense, etc. How much (1-5) do you agree with the statement?

2. Death is a natural part of life. It is important to recognize a time for death to happen and to accept it. It is noble and fitting to accept death when it approaches. Please watch this video (up to 1:00) of a peaceful death. How much (1-5) do you agree with the statement?

3. James is 87 and has late-stage kidney cancer. An intensive series of surgeries would give James a $50 \%$ chance of extending his life for one year. The surgeries would cost $\$ 60,000$. James also has the option of forgoing surgery and entering hospice care. A large number of patients in similar situations choose to forgo surgery and choose hospice. How much (1-5) do you agree with the statement?

4. John is 90 years old and presently in the midst of an extended stay in the ICU, where he requires a respirator to breathe. He does not have an advance directive to indicate his treatment preferences. The cost of keeping John alive is $\$ 6000$ per day. Medicare expenditures come from the same budget as other government programs and services. The money used to keep John alive could be used to benefit other citizens. How much (1-5) do you agree with the statement?

5. Mark is 90 years old and presently in the midst of an extended stay in the ICU, where he requires a respirator to breathe. The cost of his hospital stay is $\$ 6,000$ per day. The money that Mark's family is spending on his medical care comes out of Mark's savings and could be used instead for other things, such as to help fund the college education of Mark's grandchildren. Mark is currently unable to make decisions about his care, and thus his family is legally responsible for determining the course of action. If they continue his care, he will likely remain alive but is not 
expected to improve. The doctor has informed the family that, given Mark's condition, it would be legal and he would be willing to discontinue the use of the respirator if the family chose that option. If you would discontinue the respirator, what would you rather have your family spend money on?

6. Ensuring that children have good medical care is extremely beneficial to society. Please watch this video about preventive medical care for children. How much (1-5) do you agree with the statement?

7. George is 80 years old and has a long history of heart disease and other ailments. He had a heart attack last Wednesday and will likely die in the next two weeks without an operation. The operation costs $\$ 80,000$. George's doctors however consider that George is too frail to survive the necessary anesthesia, and have advised him against the operation. How much (1-5) do you agree with the statement?

8. Please watch the following video (to 1:04) about end of life care spending. How much (1-5) do you agree with the statement?

9. Sue has pancreatic cancer. Her doctor offers to perform an intensive surgery to remove some of the cancer. Ninety percent of people who get this operation live through it. The operation, which costs $\$ 90,000$, is covered fully by Medicare. If Sue survives, the operation is expected to extend her life by 6 months. Sue and her family decide that Sue will get the surgery. How much (1-5) do you agree with the statement?

10. Helen is 60 years old, has HER2-overexpressing breast cancer, and is currently receiving chemotherapy. A research study published in The Journal of Clinical Oncology in 2014 found that for treatment of the specific kind of breast cancer Helen has, "adding a year of Herceptin (trastuzumab) to standard chemotherapy improved overall survival by 37 percent. The addition of Herceptin also boosted 10 -year overall survival rates from 75 percent to 84 percent. And the 10 -year disease-free survival rate went from 62 percent to 74 percent for those also taking Herceptin." It would cost $\$ 64,000$ to add Herceptin to her treatment regimen for one year. How much (1-5) do you agree with the statement?

11. Jane cannot breathe without a respirator. Her doctor says Jane is dying. Her doctor also says they can continue doing everything possible to keep Jane alive in the ICU. The cost of keeping Jane alive in the ICU is $\$ 8,000$ per day and is paid for by Medicare. How much (1-5) do you agree with the statement?

12. Shelby has stomach cancer and is in in her third round of chemotherapy. Shelby has the option of hospice care, which means that Shelby will receive no treatments that attempt to cure her cancer but instead will receive treatments that aim to ease her pain and improve her daily functioning and quality of remaining life. She also has the opportunity to receive an invasive surgical procedure that would attempt to remove the tumor. The procedure would cost $\$ 100,000$ and has a $50 \%$ chance of extending her life for one year. Hospice care would cost a fraction of the procedure. How much (1-5) do you agree with the statement?

13. Robert is 93 years old and has an inoperable tumor on his neck. As a result of the tumor's continued growth, sometime within the next four months Robert will require a ventilator in order to remain alive. Unless Robert specifies in advance that he wants to receive mechanical ventilation and its associated life-saving care, 
it will not be provided. To receive mechanical ventilation and its associated life-saving care Robert would need to sign a release specifically requesting that doctors provide it. If you were the patient in this situation, would you sign the release?

\subsection{Medical scenarios \#2}

14. Erica is 75 and has a rare and fatal disease that affects the ability of her lungs to function properly. Treatment for the disease involves a series of intensive procedures which cost $\$ 40,000$ and doctors expect that the procedures will extend Erica's life by about two years. If you were the physician, would you recommend treatment?

15. Alex is 25 and was in a car accident that caused serious spinal damage. Alex will almost certainly die in the next week without an operation. If Alex receives the operation, it will cost $\$ 50,000$ and he will still be paralyzed. Imagine you are a public official in charge of managing health care costs. Would you recommend treatment in this situation?

16. Sasha is 18 and was swimming in a fast-flowing river and hit her head, causing her to fall unconscious and nearly drown. She was retrieved from the water and kept alive via CPR until the ambulance arrived. Now Sasha is in a coma. Doctors expect that they can bring Sasha out of the coma through various intensive treatments, which will cost upwards of $\$ 100,000$. Doctors say that if Sasha emerges from the coma, she will have severe brain damage for the rest of her life as a result of the period of hypoxemia. If you were the patient in this situation, would you prefer treatment?

17. Joe is 40 years old and has late stage colon cancer. With standard treatment Joe's life expectancy is 6 months. Doctors offer to give Joe a new procedure that costs $\$ 60,000$ and that may increase his life expectancy to $12-16$ months. If you were a family member, would you recommend treatment?

18. Naomi is 65 years old and has chronic obstructive pulmonary disease - a lung disease which makes it hard to breathe. Her disease is in a late stage and doctors expect that she will die within one month. Doctors have tried several drugs to slow the progression of Naomi's disease but none have worked so far. There are still a few more that they can try. If Naomi is nearing death, she has the option of getting care in the ICU at the cost of $\$ 5,000$ per day while doctors try more drugs to treat her disease. If you were the physician, would you recommend treatment? 